\title{
A escola a tempo inteiro: um estudo sobre a realidade na escola pública portuguesa
}

\author{
The full-time school: a study concerning the Portuguese public school
}

\section{La escuela a tiempo completo: un estudio de la realidad en la escuela pública portuguesa}

\begin{abstract}
Dora Sofia Ramos Fonseca'
Universidade de Aueiro, Departamento de Educação e Psicologia, Professora.
\end{abstract} http://orcid.org/0000-0003-4408-9716

\section{Marta Sofia Ramires Marques ${ }^{2}$}

Universidade de Aueiro, Mestre em Educação e Formação. https://orcid.org/0000-0003-4134-2958

Resumo: 0 Programa "Escola a Tempo Inteiro" foi implantado em Portugal, a partir de 2006, por meio das "Atividades de Enriquecimento Curricular" que, segundo o discurso político-normativo, pretendia aumentar o período de permanência das crianças nas escolas do $1^{\circ}$ ciclo do Ensino Básico, de modo a articular o funcionamento da escola com as necessidades das famílias, mas, ao mesmo tempo, proporcionar aos alunos oportunidades para a sua formação global e diversificada. Assim, este trabalho procura não só compreender como as organizações educativas concretizaram, na sua ação, as demandas do poder central, mas também problematizar se as dinâmicas pedagógicas corresponderam às necessidades e interesses das crianças, contribuindo para um desenvolvimento global e equilibrado. Metodologicamente, realizamos a investigação associando a análise documental e a metanálise de estudos sobre a realidade do contexto escolar português ao estudo de caso desenvolvido numa organização educacional (Agrupamento de Escolas Aventura). Concluímos que o Programa "Escola a Tempo Inteiro" se configurou, especialmente, como uma solução para a ocupação dos tempos em que os pais não podem estar com os filhos, não respondendo aos interesses e necessidades efetivos das crianças. A longa permanência na escola em atividades demasiado orientadas não parece contribuir para um tempo pedagogicamente rico, de modo a contribuir para o desenvolvimento global e equilibrado das crianças.

Palavras-chave: Escola a tempo inteiro, atividades de enriquecimento curricular, escola pública.

\footnotetext{
Pós-doutora em Administração Educacional pela Universidade de Aveiro; Doutora em Ciências da Educação pela Universidade de Aveiro.

2 Mestre em Educação e Formação pela Universidade de Aveiro; Licenciada em Ensino Básico pela Universidade de Aveiro.
} 
Abstract: The "Full-Time School" Program was implemented in Portugal, starting in 2006, through the "Curriculum Enrichment Activities" (CEA) which, according to the political-normative discourse, intended to increase the length of stay of children in schools in the 1st cycle of Basic Education, in order to articulate the school functioning with the family's needs, but, at the same time, provide students with opportunities for their global and diversified training. About this context, this work seeks not only to understand how educational organizations fulfilled, in their action, the demands of central power, but also to question whether the pedagogical dynamics corresponded to the children's needs and interests, contributing for their global and balanced development. Methodologically, we conducted the investigation by associating document analysis and meta-analysis of studies on the reality of the Portuguese school context with the case study developed in an educational organization (Grupamento de Escolas Aventura). We concluded that the "Full-Time School" Program was configured, especially, as a solution for the occupation of the times when parents cannot be with their children, not responding to the children's effective interests and needs. The long stay at school in overly oriented activities does not seem to contribute pedagogically rich for them, in order to contribute to the global and balanced development of children.

Keywords: Full-Time School. Curriculum Enrichment Activities. Public school.

Resumen: El programa "Escuela a tiempo completo" se implementó en Portugal, a partir de 2006, a través de las "Actividades de enriquecimiento curricular" (AEC) que, según el discurso político-normativo, pretendía aumentar la estadía de los niños en las escuelas de ler ciclo de la Educación Básica, con el fin de articular el funcionamiento de la escuela con las necesidades de las familias, pero, al mismo tiempo, brindar a los estudiantes oportunidades para su formación global y diversificada. Así, este trabajo busca no solo entender cómo las organizaciones educativas cumplieron, en su acción, las demandas del poder central, sino también cuestionar si la dinámica pedagógica correspondía a las necesidades e intereses de los niños, contribuyendo a su desarrollo global y equilibrado. Metodológicamente, realizamos la investigación asociando análisis documental y metaanálisis de estudios sobre la realidad del contexto escolar portugués con el caso de estudio desarrollado en una organización educativa (Grupamento de Escolas Aventura). Concluimos que el Programa "Escuela de Tiempo Completo" se configuró, especialmente, como una solución para la ocupación de los tiempos en que los padres no pueden estar con sus hijos, no respondiendo a los intereses y necesidades efectivos de los hijos. La larga permanencia en la escuela en actividades excesivamente orientadas no parece contribuir a un tiempo pedagógicamente rico, para contribuir al desarrollo global y equilibrado de los niños.

Palabras clave: Escuela de tiempo completo. Actividades de enriquecimiento curricular. Escuela pública.

Recebido em 30 de novembro de 2020 Aceito em 9 de março de 2021 


\section{INTRODUÇÃO}

Este artigo tem por objetivo explicar como as organizações educativas concretizaram, na sua ação, as demandas do poder central e, ao mesmo tempo, problematizar se as dinâmicas pedagógicas corresponderam às necessidades e aos interesses das crianças, contribuindo para um desenvolvimento global e equilibrado das mesmas, tendo por base as Atividades de Enriquecimento Curricular (AEC).

Para alcançar tal objetivo, na primeira seção, historicizamos o processo de implantação do Programa "Escola a Tempo Inteiro"; na segunda, buscamos refletir sobre este programa na tentativa de interpretá-lo criticamente; na terceira seção, informamos o percurso metodológico e, em seguida; na quarta seção, os resultados alcançados; por fim, encerramos com nossas considerações finais.

\section{A ESCOLA A TEMPO INTEIRO: O DISCURSO POLÍTICO/LEGAL}

Na rede pública, surge na Região Autónoma da Madeira, no ano letivo de 1995/1996, o programa Escola a Tempo Inteiro (ETI). Na altura, o projeto tinha como objetivos prioritários atender às necessidades educativas básicas e, simultaneamente, contribuir para a formação integral das crianças, com vistas a melhorar o seu sucesso escolar (QUINTANEIRO; MENDONÇA; BENTO, 2012). Entretanto, esse projeto acabou por ser introduzido no território continental no ano letivo 2005/2006 através das Atividades de Enriquecimento Curricular (AEC), que teve como primeira medida o Programa de Generalização do Ensino do Inglês no 1. ${ }^{\circ}$ ciclo do ensino básico. ${ }^{3}$ Imperava, neste momento, a urgência de corresponder aos padrões europeus, construindo uma consciência plurilingue e pluricultural desde os primeiros anos de idade, elevando, assim, a formação e as qualificações das gerações futuras. Este investimento visava a assegurar a expansão da competitividade dos trabalhadores e da economia portuguesa.

Os alunos do $3^{\circ}$ e do $4 .^{\circ}$ anos do $1^{\circ}$ ciclo, além de terem a oportunidade de usufruírem gratuitamente de ensino de língua inglesa, beneficiariam também de uma atividade de Apoio ao Estudo. Os estabelecimentos do $1 .^{\circ}$ ciclo do ensino básico passaram a estar abertos até às 17 horas e 30 minutos e, "nesse ano letivo, cerca de $76 \%$ do total de escolares alargaram o horário de funcionamento e $31 \%$ deles tiveram prolongamento de horário todos os dias." (MACHADO; CRUZ, 2014, p. 177).

\footnotetext{
3 Abrangido pelo Despacho n. $14753 / 2005$, de 24 de junho de 2005.
} 
No ano letivo seguinte, as ofertas de atividades foram ampliaram e as escolas passaram a se manterem diariamente abertas até àquele horário. Entre 2006 e 2011, ${ }^{4}$ as AEC eram selecionadas em função dos objetivos dos projetos educativos das escolas e, para esse efeito, foram criadas orientações programáticas que pretendiam ser instrumentos de trabalho para os professores das diferentes $\mathrm{AEC}$, nomeadamente, para: atividade física e desportiva, ensino da música e pra o ensino do inglês. As atividades de apoio ao estudo e de ensino de inglês eram obrigatórias e, as restantes, de caráter facultativo, pertenciam aos domínios desportivo, artístico, científico, tecnológico e das tecnologias de informação e comunicação, de ligação da escola com o meio, de solidariedade e voluntariado e da dimensão europeia da educação.

Relativamente à gestão do tempo, ficara estabelecido um período mínimo diário de 90 minutos para as AEC repartidos em dois tempos de 45 minutos ${ }^{5}$. Ficara, ainda, definido que as AEC poderiam ser promovidas pelas autarquias locais, associações de pais e encarregados de educação, instituições particulares de solidariedade social e por agrupamentos de escolas. Porém, e independentemente da entidade promotora, os agrupamentos de escolas deveriam planificar as atividades e celebrar acordos de colaboração, assim como disponibilizar os seus espaços escolares para a concretização do Programa. A supervisão dos técnicos e o acompanhamento das atividades estavam, também, ao cargo dos agrupamentos e previa-se uma articulação das AEC com as atividades curriculares, comprometendo os professores titulares de turma, sem prejuízo de que as primeiras substituíssem as áreas previstas nas Orientações Curriculares da Educação Pré-Escolar e no Currículo Nacional do Ensino Básico.

A revisão da estrutura curricular ${ }^{6}$ introduziu alterações nas $A E C$, levando a uma redução semanal de cinco a sete horas e meia. Alterações legais posteriores ${ }^{7}$ determinaram que fossem submetidas, em regra, ao período da tarde (após as atividades curriculares) e a sua oferta adaptada ao contexto da escola com o objectivo de atingir o equilibrio entre os interesses dos alunos e a formação e perfil dos profissionais que as asseguram.

Por fim, e atualmente em vigor, ${ }^{8}$ reitera-se que as AEC deveriam ser adaptadas às escolas, aos interesses dos alunos e à formação e perfil dos profissionais envolvidos e; acrescenta uma adaptação aos recursos materiais e imateriais de cada território. Outro normativo ${ }^{9}$ especifica, ainda, que, quando a entidade promotora não for um agrupamento de escolas, o apoio financeiro a conceder pelo Ministério de Educação e Ciência (MEC) não deverá

4 Ao abrigo dos Despachos: n. 12591/2006, de 16 de junho de 2006; n. 14460/2008, de 15 de maio de 2008 e; n. 8683/2011, de 28 de junho de 2011.

5 Pelo Despacho n. ${ }^{\circ} 8683 / 2011$, de 28 de junho de 2001.

6 Consagrada com o Decreto-Lei n. ${ }^{\circ} 139 / 2012$, de 5 de julho de 2012.

Via Despacho n. ${ }^{\circ} 9265-\mathrm{B} / 2013$, de 15 de julho de 2013.

8 Pela Portaria n. ${ }^{\circ} 644-A / 2015$, de 24 de agosto de 2015.

9 Desta feita, o Despacho n. . 9265-B/2013, de 15 de julho de 2013. 
ser superior ao valor correspondente a cinco horas semanais, para os $1^{\circ}$ e $2 .^{\circ}$ anos de escolaridade, e a três horas semanais, para os $3 .^{\circ}$ e $4 .^{\circ}$ ano de escolaridade.

Em 2016, mediante Ofício Circular, ${ }^{10}$ é introduzida a necessidade da oferta de AEC garantir a elevada qualidade, potenciando as vertentes lúdica, formativa e cultural aos estudantes. Para esse efeito, foram enumerados um conjunto de princípios orientadores circunscritos à planificação e implementação dessas atividades.

No que diz respeito ao financiamento, as AEC, sendo estabelecidas por meio de programas públicos, são comparticipadas pelo $\mathrm{MEC}$, sendo o financiamento atribuído às entidades promotoras e, nos primeiros anos, efectuado de acordo com o critério do custo anual por aluno." Essa comparticipação financeira era concedida mediante montantes definidos pela tutela e a Atividade de Apoio ao Estudo era responsabilidade dos agrupamentos de escolas e não era financiada.

Outro aspeto relevante era o facto de os agrupamentos de escola, não sendo entidades promotoras, deveriam providenciar o recrutamento de professores para a dinamização de atividades e receber da entidade promotora o montante correspondente aos mesmos.

Com as mudanças estruturais de $2013,^{12}$ o financiamento das AEC passou a ser efetuado de acordo com o número de alunos inscritos por atividade e o número de horas de AEC oferecidas no decurso do ano letivo, o que não excedia os 150 euros por aluno inscrito e com efetiva frequência. Posteriormente, por meio da publicação de uma portaria, ${ }^{13}$ o valor máximo de financiamento anual passou a ser de 150 euros por aluno no caso dos $1 .^{\circ}$ e $2 .^{\circ}$ anos e de 90 euros por alunos do $3 .^{\circ}$ e do $4 .^{\circ}$ anos. Importa, ainda, referir que, contrariamente ao que acontecia anteriormente, no caso de os agrupamentos de escola disponibilizarem recursos humanos para a dinamização de algumas atividades, o MEC deduziria o montante correspondente às mesmas no valor a transferir à entidade responsável.

Relativamente aos técnicos das AEC, ficou determinado que estes deverão possuir, pelo menos, uma das diversas habilitações estabelecidas pelos despachos. A cada atividade é atribuído um perfil de professor. Curiosamente, em dois diferentes despachos, ${ }^{14}$ os profissionais das AEC eram designados professores. Porém, a partir de 2011, passaram a ser considerados como técnicos, instruindo que refere os profissionais não docentes que dinamizam as $\mathrm{AEC}$ deveriam possuir formação profissional ou especializada adequada ao desenvolvimento das

10 Oficio Circular DGE/2016/3210 de 2016.

" Essa nova ordenação dos financiamentos já fora promulgada pelos Despachos número 12591/2006, de 16 de junho de 2006 , e número 14460/2008, de 15 de maio de 2008.

12 Via Despacho n. ${ }^{\circ} 9265-\mathrm{B} / 2013$, de 15 de julho.

13 Portaria n. ${ }^{\circ} 644-A / 2015$, de 24 de agosto de 2015.

14 A saber: Despachos n. $12591 / 2006$, de 16 de junho de 2006, e n. $14460 / 2008$, de 15 de maio de 2008. 
atividades programadas e ao escalão etário do público-alvo ou currículo relevante para o efeito. ${ }^{15}$ Após as alterações de 2013 , os agrupamentos de escolas, que integravam professores de carreira com disponibilidade para desenvolver o Programa das AEC lou seja, sem horário completo), poderiam atribuir a esses profissionais horas destinadas a funções nas AEC. ${ }^{16}$

No que concerne à monitorização do Programa, as AEC começaram por ser supervisionadas pela Comissão de Acompanhamento do Programa (CAP), constituída pelo Diretor-geral de Inovação e Desenvolvimento Curricular e pelos Diretores Regionais de Educação. Nesta matéria, a sua função era produzir um relatório anual de avaliação do Programa, contendo recomendações para a sua melhoria nos anos subsequentes. ${ }^{17} \mathrm{Em} 2013$, a CAP foi substituída por uma Comissão Coordenadora ${ }^{18}$ que teria as mesmas funções, mas com uma composição distinta passando a integrar dois representantes da Direção-Geral da Educação (DGE) e dois representantes da Direção-Geral dos Estabelecimentos Escolares (DGEstE). Em 2015, acrescentaram mais quatro representantes: dois da Direção-Geral da Administração Escolar (DGAE) e dois do Instituto de gestão financeira da Educação (IGeFE).

Dos vários estudos realizados e relatórios produzidos sobre as práticas das AEC, destaca-se a regulação forte do Ministério sobre as prática escolares, dificultando a flexibilização de outras possibilidades, recursos e atividades. Esta situação é justificada pela preocupação do Governo em melhorar o ensino e a aprendizagem no $1 .^{\circ} \mathrm{CEB}$, em especial, com o Programa de Generalização do Ensino do Inglês nos $3 .^{\circ}$ e $4 .^{\circ}$ anos de escolaridade, pois, como é referido, pretendia-se:

\begin{abstract}
[...] cumprir o duplo objectivo de garantir, no espaço da escola a todos os alunos de forma gratuita, a oferta de um conjunto de aprendizagens enriquecedoras do currículo e das aprendizagens, ao mesmo tempo que se concretiza a prioridade enunciada pelo Governo de promover a articulação entre o funcionamento da escola e o fornecimento de respostas úteis no domínio do apoio às famílias. (RELATÓRIO INTERCALAR DE ACOMPANHAMENTO DE AEC, 2006, p. 4).
\end{abstract}

Em suma, as AEC se conjeturam na necessidade dos tempos de permanência na escola serem pedagogicamente ricos e complementares das aprendizagens associadas à aquisição de competências básicas. ${ }^{19}$ Atualmente, e após terem sido introduzidas alterações nos mais variados domínios ao longo de dez anos, o Projeto Escola a Tempo Inteiro continua em vigor e se assenta nas seguintes vertentes: Atividades de Animação e de Apoio à Família

\footnotetext{
15 Instrução claramente presente no o artigo 9. ${ }^{\circ}$ do Despacho n. ${ }^{\circ} 9265-B / 2013$, de 15 de julho de 2013.

16 Conforme Despacho n. ${ }^{\circ}$ 9265-B/2013, de 15 de julho de 2013, e Despacho Normativo n. ${ }^{\circ} 7 / 2013$, de 11 de junho de 2013.

17 Seguindo orientação do Despacho n. $14460 / 2008$, de 15 de maio de 2008.

18 Instituída formal e oficialmente pelo Despacho n.9265-B/2013, de 15 de jultho de 2013.

19 De acordo com o Despacho n. ${ }^{\circ} 12591 / 2006$ de 16 de Junho de 2006.
} 
na Educação Pré-Escolar (AAAF); Atividades de Enriquecimento Curricular (AEC); e Componente de Apoio à Família no $1^{\circ}{ }^{\circ}$ ciclo do Ensino Básico (CAF). As AAAF ${ }^{20}$ asseguram o acompanhamento das crianças na educação pré-escolar antes e ou depois do período diário de atividades educativas e durante os períodos de interrupção destas (Artigo 3.'); as AEC são as atividades de caráter facultativo e de natureza eminentemente lúdica, formativa e cultural que incidam, nomeadamente, nos domínios desportivo, artístico, científico e tecnológico, de ligação da escola com o meio, de solidariedade e voluntariado e da dimensão europeia na educação (Artigo $7 .^{\circ}$ ) e; a CAF se traduz nas atividades destinadas a assegurar o acompanhamento dos alunos do $1 .^{\circ}$ ciclo do ensino básico antes e ou depois das componentes do currículo e das AEC, bem como durante os períodos de interrupção letiva (Artigo 5. ${ }^{\circ}$ ).

\section{A ESCOLA A TEMPO INTEIRO: REFLEXÕES EM TORNO DO PROCESSO DE IMPLEMENTAÇÃO DO PROGRAMA DE ATIUIDADES DE ENRIQUECIMENTO CURRICULAR (AEC)}

As mudanças sociais e económicas que têm vindo a ocorrer nos tempos contemporâneos e, nomeadamente, a centralidade das pressões económicas que se tem vindo a sobrepor a outras demandas, contribuem para que a educação se tenha vindo a reconfigurar.

Nóvoa (2009) tem vindo a defender que, se a escola assumir apenas a função do back to basics, o seu projeto educativo não será coerente. A aprendizagem deve ser encarada numa perspetiva multifacetada, uma vez que está muito longe de ser um processo linear. É imperativo que as crianças encontrem um sentido para a escola e construam um conhecimento que se circunscreva numa trajetória pessoal contextualizada. No entanto, reconhece-se a dificuldade sentida pelos profissionais da educação em congregar as novas missões com aquelas que, anteriormente, lhes eram atribuídas, já por si tão complexas (CORREIA; MATOS, 2001).

As novas exigências do mercado de trabalho nas sociedades contemporâneas trazem para a escola a recuperação da função de "guarda". Esta função problematizada pela academia (VILHENA; SILVA, 2002) levanta questões complexas que remetem para a gestão do tempo e do tipo de atividades e a sua necessária adequação e diferenciação tendo em conta os conhecimentos/princípios das áreas da pedagogia e da psicologia. É sabido que as sociedades têm novos desafios e um deles é compatibilizar tempos familiares e pessoais com os tempos laborais.

\footnotetext{
20 Segundo à Portaria n. ${ }^{\circ}$ 644-A/2015, de 24 de agosto de 2015.
} 
Dado o desajuste entre tempos laborais, escolares e pessoais, as familias sentem cada vez mais necessidade de encontrar formas de ocupar os tempos não escolares dos seus educandos. 0 Ministério da Educação de Portugal desenvolveu o programa AAAF na educação pré-escolar e, posteriormente, as AEC para o $1 .^{\circ}$ ciclo, "numa perspetiva de Escola a Tempo Inteiro" (MACHADO; CRUZ, 2014, p. 174), credibilizando, assim, o seu papel social e educativo (COSME; TRINDADE, 2007). Note-se que imperava a preocupação de não só colocar as escolas ao serviço da aprendizagem dos alunos, como, também, de melhorar os resultados escolares, que não estavam bem conotados em estudos nacionais e internacionais (FERREIRA; OLIVEIRA, 2007).

De acordo com a então Ministra de Educação, Maria de Lurdes Rodrigues, a escola pública "pode e deve fazer a diferença". Para isso, seriam necessárias "políticas públicas de educação orientadas para a promoção da equidade da eficiência e da qualidade." (PIRES, 2013, p. 111). A criação do Programa ETI se assentava na necessidade de acrescentar às funções da escola a função de guarda e custódia das crianças, numa perspetivo de apoio às famílias (MACHADO; CRUZ, 2014), reiterando a democratização do ensino, garantindo o direito a uma justa e efectiva igualdade de oportunidades no acesso e sucessos escolares e ampliando a formação das crianças, através de atividades enriquecedoras do currículo (PEREIRA, 2010).

0 discurso político-normativo, não abandonando uma gramática democrática, estaria visivelmente ao serviço de uma agenda económica. Segundo os relatórios de avaliação produzidos periodicamente, é percetível que, numa primeira instância, o projeto ETI veio promover a equidade social, na medida em que permite que todas as crianças, independentemente da sua condição sócio económica, beneficiem de um leque mais alargado de experiências educativas (COSME; TRINDADE, 2007). É o chamado "dispositivo de democratização do acesso à educação não formal a todas as crianças." (PEREIRA, 2010, p. 221). Contudo, outros estudos sobre a implementação do Programa revelam que este parece ter vindo a reduzir o tempo de brincadeira das crianças, levando à pedagogização do lazer (MOURAZ; VALE; MARTINS, 2012) e, inclusivamente, impedir um autêntico usufruto de tempos livres, já que o sujeito aprendente fica impossibilitado de decidir o que fazer nesse seu tempo (PIRES, 2007).

Note-se que, no $1^{\circ}$ ciclo do ensino básico, as crianças passam obrigatoriamente cerca de cinco horas por dia na sala de aula e, pelo menos, 30 minutos no intervalo da manhã, o que corresponde a cinco horas e meia do seu dia na escola. No caso de as crianças almoçarem na escola e frequentarem as AEC após o período curricular, percebemos que as crianças permanecem durante oito horas e meia na escola, o que ultrapassa um dia normal de trabalho de um adulto. A situação se agrava nos casos de os pais os deixarem na escola antes das nove horas e os forem buscar depois das 17 horas e 30 minutos. Importa ainda referir que, na maior parte dos casos, as crianças frequentam outras atividades fora do contexto escolar. Digamos que, em muitos casos, as crianças deixaram de ter tempos para gerirem suas vidas livremente e estando, por isso, sempre sujeitas a orientações definidas pelos adultos. 
Alguns autores têm vindo a explorar a importância do tempo livre para o desenvolvimento de várias capacidades do sujeito aprendente. Entre elas, destacamos a autonomia e as relações interpessoais. Araújo (2009) considera que, com a ETl, muitas vezes, são impostas atividades à criança sem que thes seja dada a oportunidade de escolher livremente - que fazer. A autora entende que "escolher é ter a possibilidade de, no seu tempo livre, poderem iniciar uma actividade, mas também desistir, se não se adaptarem, e mudar para outra." (ARAÚJO, 2009, p. 122). Nesta linha, surge ainda a necessidade de valorizar, na infância, os tempos destinados ao brincar de forma livre e a sua importância para o desenvolvimento psicossocial dos sujeitos. Apesar de não explorarmos de forma aprofundada esta questão, queremos salientar, neste artigo, a importância do brincar como uma atividade imprescindível para o desenvolvimento global da criança e alertar para que a implementação das AEC pode não estar a contemplar esta necessidade suficientemente. Relembrando Cardoso (2012, p. 32), nas atividades livres, nas suas brincadeiras, a criança fica exposta a novas experiências e possibilidades de atuação "no e sobre o mundo" adquirindo informações, conhecimentos, habilidades e até entendimentos desenvolvidos de forma autonómica e que fortalecem a confiança em si mesmo e as suas capacidades cognitivas, psicomotoras e sociais (ARAÚJ0, 2009).

Vários autores têm vindo a revelar a importância da dinâmica do brincar e do jogo lúdico na infância para o desenvolvimento do pensamento abstrato, favorecendo que a criança compreenda melhor os outros e consiga mais facilmente gerir autonomamente as suas próprias ações (CARDOSO, 2012). Em alguns momentos, o lúdico é referenciado nos normativos alusivos às AEC como uma caraterística que deverá marcar a natureza das atividades a desenvolver. A ludicidade diz respeito à essência do ser humano que se manifesta através de ações como "brincar, jogar, recrear, lazer e construir artefactos lúdicos e de criatividade." (LOPES, 2004, p. 11). Ainda que de forma sucinta, apresentámos algumas ideias que nos levaram a refletir na importância do tempo livre, do brincar e das experiências lúdicas em tempo de infância e que deverão ser tidas em conta na problemática que apresentamos neste trabalho.

Um outro aspeto que exige a nossa reflexão prende-se com as questões curriculares com as quais as AEC estão intrinsecamente ligadas. Currículo é, para Roldão (2013), o conjunto de aprendizagens que socialmente se entendem necessárias tendo em conta as condições contextuais, cabendo à escola a responsabilidade de garantir, organizar e gerir-lás. De certa forma, o currículo transparece os valores de uma sociedade, o seu conceito de ciência e a hierarquização de determinadas áreas científicas (PARDAL, 1993). Nesse currículo, ou corpo de aprendizagens (ROLDÃ0, 2013), estão circunscritos os tempos considerados letivos e ocorrem, principalmente, em contextos educativos formais, como é o caso da sala de aula. Contudo, Sacristán (2000) amplia o seu alcance e defende que o currículo é muito mais do que um corpo de conhecimentos, uma vez que engloba múltiplos agentes com dinâmicas e mecanismos diversos, numa mescla de práticas que, por vezes, refletem conjeturas emancipatórias. Essa emancipação é a concretização do currículo em 
ação (FELÍCIO; POSSANI, 2013). De uma forma simplista, as ações realizadas na escola, mais concretamente na sala de aula, podem ser consideradas curriculares formais e, aquelas que se realizam fora do espaço considerado escolar, poderão ser entendidas como curriculares não formais (CASCAIS; FACHÍN TERÁN, 2014).

Alguns autores, invocando a perspetiva crítica do currículo, não separam esses espaços - mostrando que, no espaço escolar, ocorrem aprendizagens não formais também (PACHECO, 2003). Seguindo a perspetiva técnica do currículo, podemos afirmar que, do ponto de vista do currículo formal, identificaríamos os tempos letivos que implicam algo estruturado, obrigatório, previamente planificado e com uma intenção pedagógica subjacente. Por outro lado, os tempos não letivos, onde a criança deveria desenvolver atividades de forma mais livre e menos "escolarizantes", poderiam ser entendidos como currículo não formal. Por outras palavras, segundo Vilhena e Silva (2002, p. 52), "quer dizer que esse tempo deveria ser dedicado a que a criança tivesse inteira liberdade de escolher o que deseja fazer", proporcionando a sua realização pessoal (GOMES et al., 2002). Dos vários estudos e relatórios de avaliação produzidos em torno da frequência das $\mathrm{AEC}$, percebemos que existem várias posições. Uma delas, desde a implementação das AEC, que as várias reflexões em torno do Programa ETI, mostram que ele satisfaz as necessidades das famílias (PEREIRA, 2010).

Ainda assim, apontam-se algumas vulnerabilidades, tais como: i) a adoção de soluções homogéneas para todos os agrupamentos, sem ter em conta os vários contextos; ii) a preferência de determinadas atividades, devido ao financiamento, em prol de outras (COSME; TRINDADE, 2007); iii) a tendente compartimentação do $1^{\circ}$ ciclo em disciplinas e a escolarização das atividades AEC (FERREIRA; OLIVEIRA, 2007); iv) a imposição das mesmas atividades a todas as crianças, do mesmo ano de escolaridade ou faixa etária, sem que lhes seja dada a oportunidade de escolher (ARAÚJO, 2009) e; v) a falta de articulação e de sustentação teórica entre a educação formal e a não formal." (PEREIRA, 2010, p. 224). No que diz respeito à gestão e seleção de atividades, nota-se uma certa tendência em selecionar as atividades com mais potencial de financiamentos, indiciando uma certa "lógica mercantil" com consequências de ofertas semelhantes nos diferentes agrupamentos de escolas (PIRES, 2007; MOURAZ; VALE; MARTINS, 2012).

Por outro lado, as AEC circunscrevem-se às áreas das expressões e da atividade física e desportiva, levando a que, muitas vezes, estas áreas sejam descuradas ao nível do currículo formal, pois parecem ter sido remetidas para as $\mathrm{AEC}$, embora não oficialmente. Esse facto leva a que as crianças, em período de currículo dito formal, dediquem-se a áreas, consideradas por alguns profissionais de educação, "nucleares", como é o caso da língua portuguesa e da matemática. É o chamado retorno do back to basics (MOURAZ; VALE; MARTINS, 2012) e que fica evidente quando percecionamos que muitos profissionais de educação continuam a admitir que a principal função do $1^{\circ}$ ciclo é a preparação para os ciclos subsequentes (COELHO; TRINDADE, 2007). 
Também nesta lógica de produtividade académica, as AEC têm vindo a assumir um registo escolarizante de forma a contribuir para perfis de excelência, contribuindo "para um abreviar da infância, sob a justificação da (sobre)vivência num mundo em constante transformação, reivindicando uma formação para a flexibilidade, para a adaptabilidade e para a competição imposta pelas normas de mercado." (COELHO; TRINDADE, 2007). Porém, o dano mais flagrante é a possibilidade de híper-escolarização das crianças que as frequentam. Apesar de haver uma intenção de cariz lúdico-recreativo na sua essência, a verdade é que predomina a perspetiva transversal de enriquecimento e complemento curricular, muitas vezes, desenvolvida no mesmo espaço e com o mesmo grupo/turma. A questão que se coloca é se será mesmo necessário um alargamento do espaço e do tempo da educação formal, até porque não há uma correlação entre o tempo despendido em atividades letivas e o desempenho escolar dos alunos (COSME; TRINDADE, 2007).

Do mesmo modo, Roldão (2013, p. 32) alerta para a premência de

[...] sensatez na gestão do tempo e dos processos, com atividades interessantes, não assimilando o formato de aula da escola curricular, de forma a não fazer das vertentes curriculares e extracurricular como «dois mundos incomunicantes» nem transformá-los em «dois mundos iguais.

Um aspeto positivo a destacar nos vários estudos sobre a questão do Programa ETI são as alterações que as AEC vieram introduzir no regime da monodocência. 0 professor titular de turma (PTT) ingressa no desafio da articulação e da integração curricular, com vista a minorar a balcanização curricular (MACHAD0; CRUZ, 2014). De relembrar que, nos primeiros anos de implementação das AEC, o apoio ao estudo era atividade obrigatória para todos os alunos e ministrada pelo PTT.

Do ponto de vista oficial, os relatórios de acompanhamento de avaliação das AEC, produzidos em 2008/2009 e 2010/2011 pelo MEC, já alertavam para alguns aspetos, nomeadamente: i) a necessidade de desenvolver mecanismos que possibilitem uma melhor integração dos alunos com necessidades educativas especiais nas AEC; ii) os elevados custos do programa e a insuficiência das verbas atribuídas; iii) utilização de programas pré-concebidos pelas entidades promotoras, em que se questiona a sua adequação às orientações programáticas das AEC ao Currículo Nacional do Ensino Básico e aos Projetos Educativos das Escolas; iv) descuramento, pelo PTT, de áreas do currículo (Expressões artísticas e físico-motoras) a favor das AEC; v) a criação de condições mais favoráveis aos professores das $\mathrm{AEC}$, que facilitem o recrutamento e a fidelização dos docentes, assim como eventuais substituições, vi) um maior incentivo à utilização das Novas Tecnologias da Informação e Comunicação no $1^{\circ}$ ciclo por parte de professores e alunos; vii) recurso à flexibilização dos horários em função dos interesses dos alunos e das famílias e não apenas 
em função da gestão dos espaços e dos recursos humanos; viii) aposta na sensibilização dos encarregados de educação, de modo a promover a assiduidade e o compromisso estabelecido para com as $\mathrm{AEC}$; ix) a rentabilização de recursos, combinando anos de escolaridade, mas criando constrangimentos ao nível do bom funcionamento das atividades; $x$ ) a carência de espaços adequados ao desenvolvimento das AFD; xil a premência de rentabilizar outros espaços do agrupamento, com o intuito de evitar permanecer sempre na sala de aula e "curricularizar" as AEC e; xii) um progresso verificado na articulação com o PTT, com um caráter cada vez mais frequente e formal.

É percetível o impacto das AEC no desenvolvimento das capacidades dos alunos, nomeadamente no aumento dos seus conhecimentos e aptidões e na melhoria dos métodos de estudo. Constata-se, ao mesmo tempo, que as AEC estão mais integradas nas dinâmicas gerais das escolas e que, por esse motivo, as atividades selecionadas se adequam melhor ao contexto local e às faixas etárias dos alunos.

Devido às mudanças estruturais, registou-se um aumento do número de agrupamentos de escola que se assumiram como entidades promotoras das AEC e subiu também o número de professores do quadro a desenvolve-las pela primeira vez. Contudo, este aspeto trouxe algumas preocupações, pois, apesar de os docentes que exercem funções nas AEC pertencerem ao quadro dos agrupamentos de escolas lo que pode ser importante para o conhecimento da realidade contextual), são maioritariamente dos 2 . $^{\circ}$ e do 3. ciclos e não têm, de uma forma geral, formação para este trabalho,] nem experiência com crianças das faixas etárias que frequentam este programa.

Outro constrangimento diz respeito aos atos administrativos, em particular, à contratação dos técnicos que, por vezes, impedem que as AEC se iniciem em simultâneo com as atividades letivas. 0 relatório supramencionado recomenda ainda: i) que se garanta o cumprimento do Currículo Nacional do Ensino Básico no período letivo e não durante o tempo destinado às $\mathrm{AEC}$; ii) uma seleção das $\mathrm{AEC}$ tendo em conta os contextos e as idades dos alunos; iii) incluir nos Programas Educativos Individuais (PEl) dos alunos as condições de frequência das $A E C$; iv) adoção da vertente lúdica das $A E C$, encarando-a como uma das suas mais valias e; v) a inclusão das $\mathrm{AEC}$, independentemente das entidades promotoras, nos processos de autoavaliação dos agrupamentos de escolas.

Reconhece-se, a parti de 2014 e 2015, que as AEC desenvolvem, efetivamente, as capacidades dos alunos, contribuindo para os conhecimentos, aptidões e melhoria dos métodos de estudo dos alunos e reforça-se uma maior adequação das atividades oferecidas aos contextos locais e às faixas etárias das crianças. Pela primeira vez, assume-se que a contratação dos técnicos é problemática, devido aos horários reduzidos e pouco apelativos, o que origina mobilidade e substituição recorrente destes profissionais. 
No ano letivo de 2015/2016, foram disponibilizados o "inquérito no âmbito das AEC" e o questionário "Atividades de Enriquecimento Curricular 2015/2016", pela Comissão Coordenadora, com o objetivo de recolher informação sobre a qualidade das ofertas facultadas. Estes instrumentos eram de preenchimento online e não obrigatório. Este processo não foi validado, pois as respostas concentraram-se nos elementos da direção dos agrupamentos de escolas, não permitindo ter a perceção das opiniões de outros atores que intervêm no processo. No ano letivo seguinte, voltou a realizar-se o processo de avaliação utilizando o mesmo instrumento de recolha de dados e que foi disponibilizado, de forma facultativa, a todas as unidades orgânicas que integrassem o Programa ETI com a concretização das AEC.

Os resultados obtidos permitiram retirar as seguintes conclusões: i) as AEC continuam a constituir-se parte integrante das dinâmicas das escolas; ii) nem todas as entidades promotoras consideram a opinião dos alunos, encarregados de educação e parceiros locais para a decisão das atividades a oferecer; iii) a articulação horizontal é uma prática comum em muitas unidades orgânicas, embora o mesmo não se processe com a articulação vertical; iv) predomina a avaliação quantitativa em detrimento da avaliação formativa e participativa; v) na maioria das entidades, há supervisão das AEC, mas deve apostar-se numa supervisão mais técnica/pedagógica, de modo a potenciar a qualidade e a articulação horizontal, vertical e externa e; vil deverão ser contempladas as AEC nas avaliações interna e externa dos agrupamentos de escolas.

\section{BREUE APRESENTAÇÃO DO PERCURSO METODOLÓGIICO}

A abordagem metodológica privilegiada foi de natureza qualitativa. Optamos pela realização de um Estudo de Caso, pois pretendíamos conhecer, descrever e analisar uma problemática específica no próprio contexto organizacional. Pretendíamos obter conhecimento sobre as dinâmicas das $\mathrm{AEC}$, nomeadamente descobrir o que há de mais peculiar na realidade contextualizada sobre as atividades, os professores, os espaços, os recursos e, ainda mais importante, escutar o que os diferentes intervenientes têm a dizer sobre elas.

0 contexto do estudo foi o Agrupamento de Escolas Aventura, ${ }^{21}$ uma unidade organizacional situada na zona centro do país, mais concretamente no litoral oeste de Portugal. Com uma zona de influência que abrange três freguesias com uma área global de 35,45 Km2 e um total de 8117 habitantes. 0 agrupamento é constituído por uma escola básica de $2^{\circ}$ e $3^{\circ}$ ciclos, que é a sede do agrupamento, cinco escolas do $1 .^{\circ}$ ciclo do ensino básico e cinco

\footnotetext{
21 De modo a preservar o seu anonimato, atribuímos um nome fictício ao Agrupamento de Escolas (unidade organizacional que
} integra várias subunidades/escolas públicas de diferentes ciclos da educação pré-escolar e ensino básico. 
estabelecimentos de educação pré-escolar. 0 Agrupamento de Escolas Aventura é frequentado por 733 alunos, o que se traduz em 26 turmas distribuidas entre o pré-escolar e o $3^{\circ}$ ciclo.

0 público-alvo do estudo integrou elementos da direção, professores titulares de turma, técnicos das AEC, encarregados de educação e alunos. No processo de recolha de dados, utilizámos inquéritos por questionário com os encarregados de educação, entrevistas com os profissionais de educação do agrupamento e grupos focais com as crianças, em diferentes turmas. A análise de conteúdo foi a principal técnica utilizada para o processo de análise de dados embora tenha, ainda, sido utilizado o tratamento estatístico através de programas informáticos específicos, para as questões fechadas do inquérito por questionário aplicado aos encarregados de educação.

0 estudo empírico tinha como objetivos: i) Compreender as motivações e critérios que levam o agrupamento a selecionar determinadas atividades para as $\mathrm{AEC}$; ii) Conhecer a gestão dos tempos, espaços e recursos nas AEC; iii) Averiguar como são orientadas, monitorizadas e avaliadas as AEC; iv) Identificar o perfil dos profissionais das AEC; v) Conhecer a opinião da comunidade escolar sobre as $\mathrm{AEC}$; vi) ldentificar constrangimentos e potencialidades da implementação do Programa das AEC no Agrupamento de Escolas Aventura.

\section{APRESENTAÇÃO GERAL DOS RESULTADOS}

Apresentamos, neste artigo, apenas as conclusões do estudo tendo em conta os objetivos atrás referidos. Para o objetivo "Compreender as motivações e critérios que levam o agrupamento a selecionar determinadas atividades para as AEC", concluímos que as atividades são determinadas pela direção, tendo como referência aquilo que os professores titulares percecionam sobre o que os seus alunos precisam e as suas preferências e dos encarregados de educação. Segundo os membros da direção, é feito um esforço para que as atividades escolhidas sejam essencialmente lúdicas e diferentes das realizadas em sala de aula.

Para o objetivo "Conhecer a gestão dos tempos, espaços e recursos nas AEC", percebemos que o Ministério da Educação de Portugal define o horário e a duração das atividades. As atividades são realizadas no recinto escolar, muitas vezes, na mesma sala de atividades/aulas. Os tempos destinados às AEC são definidos após o terminus dos tempos considerados letivos. Em relação aos recursos humanos, as AEC são geridas por profissionais de educação (docentes) e designados por técnicos. Em relação à gestão de recursos materiais, a direção do Agrupamento de Escolas Aventura disponibiliza, sempre que as suas verbas o permitem, os materiais que são solicitados pelos técnicos das AEC. 
Para o objetivo "Averiguar como são orientadas, monitorizadas e avaliadas as AEC", os dados sugerem que a avaliação é feita pelos professores titulares, através do feedback dos alunos e técnicos, e é comunicada à direção. A direção também avalia o processo, tendo em conta o feedback dos encarregados de educação e outros indicadores como as desistências e pedidos de frequência que surgem ao longo do ano letivo.

Para o objetivo "Identificar o perfil dos profissionais das AEC", percebemos que os técnicos das AEC são professores licenciados, alguns com mestrados e pós-graduações. Não possuem vínculo profissional porque são professores contratados e a grande maioria não consegue colocação no quadro do agrupamento de escolas (função pública) nas disciplinas ou níveis educativos para os quais têm habilitação profissional. No que às $A E C$ diz respeito, estes são contratados apenas como técnicos e a direção prioriza a seleção daqueles que têm formação específica na área que pretendem dinamizar, muito embora nem sempre seja possível devido à falta de candidaturas para áreas mais específicas como ioga e artes performativas (exemplos de atividades do Agrupamento de Escolas Aventura). Há um professor do quadro de escola a dinamizar AEC de forma a completar horário e que é uma imposição do MEC.

Para o objetivo "Conhecer a opinião da comunidade escolar sobre as AEC", percebemos que a maioria dos profissionais de educação (titulares de turma, técnicos AEC e direção) considera que as $\mathrm{AEC}$ não beneficiam muito as crianças, pois, segundo alguns relatos, provocam cansaço e não permitem que as crianças tenham tempo para brincar livremente. Por outro lado, a maioria dos encarregados de educação considera que as crianças se beneficiam com as AEC. A maioria das crianças gosta de frequentar as AEC, embora muitas afirmem que não gostam de algumas atividades. Em relação às suas preferências, muitas destacam os recursos materiais que são utilizados em atividades desportivas dando conta que mais do que as atividades em si, os materiais utilizados são relevantes. Muitas crianças revelaram que não gostam das atividades de música e de "pilates", opções feitas pelo Agrupamento de Escolas Aventura.

Para o objetivo "Identificar constrangimentos e potencialidades da implementação do Programa das AEC", as análises indicam que as potencialidades das AEC resumem-se ao facto de os pais terem onde deixar os filhos, de forma gratuita, depois de as atividades letivas terminarem. Os constrangimentos identificados pelos profissionais de educação remetem para os espaços físicos e os recursos materiais; o tipo de contratação dos técnicos; a dificuldade em gerir problemas de indisciplina e a falta de articulação entre as AEC e as atividades desenvolvidas ao nível dos tempos destinados ao currículo formal. 


\section{CONSIDERAÇÕES FINAIS}

Com a implementação do Programa Escola a Tempo Inteiro, o Ministério da Educação de Portugal propôs-se a solucionar o problema de guarda das crianças, enquanto os pais executam as suas atividades profissionais. Pretendeu, também, o acesso gratuito de todas as crianças a um conjunto de atividades que thes possam enriquecer o currículo escolar. No entanto, se este programa se configura numa solução para os tempos em que os pais não podem estar com os filhos, também suscita outras questões relacionadas com a qualidade desse tempo e com as consequências dessa longa permanência na escola em atividades orientadas.

Perquirindo o objetivo de explicar como as organizações educativas vinculadas ao Programa Estcola de Tempo Integral concretizaram suas ações, verifica-se que as crianças possuem pouca liberdade para brincar livremente e que as atividades que frequentam nem sempre são fruto das suas escolhas. Foi-lhes aumentado o tempo em que permanecem na escola em atividades que lhes são facultadas, mas que implicam quase sempre uma excessiva estruturação, sendo os seus tempos livres diminutos. Reconhecendo a necessidade do brincar livremente e do jogo lúdico para o desenvolvimento das crianças, consideramos, tendo em conta os vários estudos realizados e a perceção dos atores implicados nestes processos, que as $\mathrm{AEC}$ parecem não contribuir para o enriquecimento destas atividades de lazer e para a conservação de tempo livre na infância. As necessidades e interesses das crianças parecem estar em segundo plano.

0 estudo desenvolvido no Agrupamento de Escolas Aventura corrobora as tendências já identificadas por outros estudos. As crianças, de uma forma geral, parecem gostar de frequentar as atividades, embora muitas façam alguns comentários negativos em relação a algumas atividades desenvolvidas, indiciando que o que a direção pensa serem as suas preferências não coincide com os verdadeiros interesses das próprias. Os encarregados de educação parecem ser aqueles que estão mais satisfeitos com o Programa ETI. A maior parte dos profissionais de educação não considera que as AEC sejam verdadeiramente importantes para as crianças e considera, ainda, que existem muitos constrangimentos no processo de implementação das AEC, em especial, de ordem burocrática, nomeadamente na contratação de técnicos e gestão de recursos materiais.

Este estudo leva-nos a concluir que é necessário proceder a muitas alterações estruturais e de cultura de trabalho dos docentes para que se possa responder, efetivamente, aos interesses e necessidades reais das crianças, sendo certo que, até ao momento, o Programa ETI parece apenas responder aos encarregados de educação que precisam de ocupação para as suas crianças para que possam exercer as suas funções profissionais. 
A longa permanência na escola em atividades demasiado orientadas não parece ajudar para um tempo pedagogicamente rico de modo a contribuir para o desenvolvimento global equilibrado das crianças. Apesar de ser evidente uma consciencialização da direção e dos professores do Agrupamento de Escolas Aventura para a problemática e sobre a necessidade de fazer alterações profundas na operacionalização do Programa ETl, a realidade parece evidenciar que há ainda um longo caminho a percorrer entre o plano das intenções e o plano da ação.

\section{REFERÊNCIAS}

ARAÚJO, M. J. Crianças ocupadas. Lisboa: Prime Books, 2009.

CARDOSO, M. G. Criando contextos de qualidade em creche: ludicidade e aprendizagem. Tese de doutoramento. Braga: Universidade do Minho, Instituto de Educação, 2012.

CASCAIS, M. G. A.; FACHÍN-TERÁN, A. Educação formal, informal, não formal na educação em ciências. Ciência em Tela, n. 2, p. 1-10, 2014.

COELHO, C.; TRINDADE, R. Actividades de enriquecimento curricular: riscos e potencialidades de uma "Escola a Tempo Inteiro". Porto: Faculdade de Psicologia e Ciências da Educação da Universidade do Porto, 2007.

CORREIA, J. A.; MATOS, M. Solidões e solidariedades nos quotidianos dos professores. Porto: Edições ASA, 2001.

COSME, A.; TRINDADE, R. Escola a tempo inteiro - escola para que te quero? Porto: Profedições, 2007.

FELÍCIO, H. M.; POSSANI, L. F. Análise crítica de currículo: um olhar sobre a prática pedagógica. Currículo sem Fronteiras, v. 13, n. 1, p. 129-142, 2013.

FERREIRA, F. I.; OLIVEIRA, J. Escola e políticas educativas: lugares incertos da criança e da cidadania. Perspectiva, v. 25, n. 1, p. 105-126, 2007.

GOMES, M. et al. Crescer em comunidade: estratégias de educação não formal à descoberta de culturas juvenis. Lisboa: Ministério da Educação, 2002.

LOPES, C. Ludicidade humana - contributos para a busca dos sentidos do humano. Aveiro: Universidade de Aveiro, 2004.

MACHADO, J.; CRUZ, A. Atividades de enriquecimento curricular no $1^{\circ}$ Ciclo do Ensino Básico. Currículo sem Fronteiras, v. 14, n. 1, p. 173-191, jan./abr. 2014. 
MOURAZ, A.; VALE, A.; MARTINS, J. Atividades de enriquecimento curricular: o difícil equilibrio entre a resposta social e a qualidade educativa. Configurações, v. 10, 2012.

NÓVOA, A. Educação 2021: para uma história do futuro. Lisboa: Universidade de Lisboa, 2009.

PACHECO, J. A. Teorias curriculares: politicas, lógicas e processos de regulação regional das práticas curriculares. Seminário o currículo regional, Açores: Terceira, 2003.

PARDAL, L. A. A escola, o currículo e o professor. Aveiro: Universidade de Aveiro, 1993.

PEREIRA, M. R. Municípios e educação em Portugal: um processo de "municipalização"? 2010. Dissertação (Mestrado em Ciências da Educação) - Universidade de Aveiro, Aveiro, 2010.

PIRES, C. A. Construção de sentidos em política educativa: o caso da Escola a Tempo Inteiro. Revista de Ciências da Educação, n. 4, p. 77-86, 2007.

PIRES, C. A. "Escola a Tempo Inteiro" - monopolização de um serviço público de educação pela escola pública e formas de privatização. In: VENTURA, A.; COSTA, J.; NETO MENDES, A. (org.). Escolas, competição e colaboração: que perspetivas? Aveiro: Universidade de Aveiro, 2013.

QUINTANEIRO, A.; MENDONÇA, A.; BENTO, A. A autonomia das escolas básicas do 1. ciclo com pré-escolar da Região Autónoma da Madeira, da teoria à prática. In: SIMPÓSIO DE ORGANIZAÇÃO E GESTÃO ESCOLAR, 7., 2012, Aveiro. Anais [...] Aveiro: Universidade de Aveiro, 2012.

RELATÓRIO INTERCALAR DE ACOMPANHAMENTO DE AEC. Actividades de Enriquecimento Curricular. IS. l.: s. n., 2006. Disponivel em: https://www.dge.mec.pt/sites/default/files/Basico/AEC/aec_relatorio_intercalar_2006.pdf. Acesso em: 14 dez. 2020.

ROLDÃO, M. C. Desenvolvimento do currículo e melhoria dos processos e resultados. In: MACHADO, J.; ALVES, J. M. (org.). Melhorar a escola - sucesso sscolar, disciplina, motivação, direcção de escolas e políticas educativas. Porto: Faculdade de Educação e Psicologia da Universidade Católica Portuguesa, 2013.

SACRISTÁN, J. G. 0 currículo: uma reflexão sobre a prática. Porto Alegre: Artmed, 2000.

VILHENA, G.; SLLVA, M. I. Organização da componente de apoio à família. Lisboa: Ministério da Educação, 2002.

Endereço para correspondência: Universidade de Aveiro, Departamento de Educação, campus de Santiago, 3810-193, Aveiro, Portugal; dorafonseca@ua.pt 